\title{
Impact of Off-Hour Hospital Presentation on Mortality in Different Subtypes of Acute Stroke in Korea : National Emergency Department Information System Data
}

\author{
Taikwan Kim, ${ }^{1}$ Cheolsu Jwa ${ }^{2}$ \\ Department of Neurosurgery, Incheon Hospital 21, Incheon, Korea \\ Department of Neurosurgery, ${ }^{2}$ National Medical Center, Seoul, Korea
}

Objective : Several studies have reported inconsistent findings among countries on whether off-hour hospital presentation is associated with worse outcome in patients with acute stroke. However, its association is yet not clear and has not been thoroughly studied in Korea. We assessed nationwide administrative data to verify off-hour effect in different subtypes of acute stroke in Korea.

Methods : We respectively analyzed the nationwide administrative data of National Emergency Department Information System in Korea; 7144 of ischemic stroke (IS), 2424 of intracerebral hemorrhage (ICH), and 1482 of subarachnoid hemorrhage (SAH), respectively. "Off-hour hospital presentation" was defined as weekends, holidays, and any times except 8:00 AM to 6:00 PM on weekdays. The primary outcome measure was in-hospital mortality in different subtypes of acute stroke. We adjusted for covariates to influence the primary outcome using binary logistic regression model and Cox's proportional hazard model.

Results : In subjects with IS, off-hour hospital presentation was associated with unfavorable outcome (24.6\% off hours vs. $20.9 \%$ working hours, $p<0.001)$ and in-hospital mortality ( $5.3 \%$ off hours vs. $3.9 \%$ working hours, $p=0.004)$, even after adjustment for compounding variables (hazard ratio [HR], 1.244; 95\% confidence interval [Cl], 1.106-1.400; HR, 1.402; 95\% Cl, 1.124-1.747, respectively). Off-hours had significantly more elderly $\geq 65$ years ( $35.4 \%$ off hours vs. $32.1 \%$ working hours, $p=0.029$ ) and significantly more frequent intensive care unit admission (32.5\% off hours vs. $29.9 \%$ working hours, $p=0.017$ ) than working hours. However, off-hour hospital presentation was not related to poor short-term outcome in subjects with $\mathrm{ICH}$ and SAH.

Conclusion : This study indicates that off-hour hospital presentation may lead to poor short-term morbidity and mortality in patients with IS, but not in patients with $\mathrm{ICH}$ and SAH in Korea. Excessive death seems to be ascribed to old age or the higher severity of medical conditions apart from that of stroke during off hours.

Key Words : Acute stroke · Cerebral hemorrhage · Mortality · Off-hours · Subarachnoid hemorrhage.

\section{INTRODUCTION}

Acute stroke is a medical and subsequent surgical emergen- cy, which needs time-dependent evaluation and therapy by highly trained, skilled neurologists or neurosurgeons, nurses and other paramedics. Off-hour time may first lead to delay of

- Received : April 28, 2020 • Accepted : June 25, 2020

- Address for reprints : Cheolsu Jwa

Department of Neurosurgery, National Medical Center, 245 Eulji-ro, Jung-gu, Seoul 04564, Korea

Tel : +82-2-2260-7279, Fax : +82-2-2262-4869, E-mail : chsjwa@daum.net, ORCID : https://orcid.org/0000-0002-7688-2842

This is an Open Access article distributed under the terms of the Creative Commons Attribution Non-Commercial License (http://creativecommons.org/licenses/by-nc/4.0) which permits unrestricted non-commercial use, distribution, and reproduction in any medium, provided the original work is properly cited. 
hospital presentation after acute stroke. Off-hours may also increase time interval from computed tomography (CT) scanning to interventional procedure ${ }^{17)}$. Because specialists are usually at home during off hours, fast decision-making and subsequent intervention or operation may be delayed ${ }^{25}$. Off hours may decrease performance skills of interventionalist or neurosurgeon owing to change of normal biological rhythm and physical or mental fatigue ${ }^{11)}$. As a result, off-hour hospital presentation may increase the probability of unexpected complications $^{1)}$ or frequent medical errors ${ }^{3)}$. This phenomenon is well known as "off-hour effect" which been believed to result in worse outcome in time-dependent critical conditions such as acute stroke $e^{4)}$, acute myocardial infarction ${ }^{16}$.

There have been incoherent results among countries on impact of off-hour admission on clinical outcome after acute str $\mathrm{oke}^{4,5,10,13,15,18,19,22,24)}$. Its relation has not yet been thoroughly studied in Korea. We analyzed nationwide administrative data to verify off-hour effect in different subtypes of acute stroke in Korea.

\section{MATERIALS AND METHODS}

\section{Study population}

This study was approved by the Institutional Review Board/
Ethics Committee of National Medical Center (IRB No. H-1902-099-003). We used the nationwide administrative data from the National Emergency Department Information System (NEDIS) between January 2010 and December 2011. This data is comprised of 26 hospitals that are qualified as wide regional or regional emergency medical center located 13 regional states and five metropolitan cities in Korea excluding the metropolitan area of Seoul-Incheon-Gyeonggi districts. Subjects who visited emergency medical center within 24 hours of symptom onset were the scope of this registration data. All patients were adequately treated after diagnosis by CT scan or magnetic resonance imaging scan. Inclusion criteria were defined as ischemic stroke (IS), intracerebral hemorrhage (ICH), subarachnoid hemorrhage (SAH) coded as I63, I61, 160 grounded on the World Health Organization's International Classification of Diseases, 10th revision. Exclusion criteria were defined as subjects with less than 18 years of age, causes of stroke sequelae and death on arrival.

A total of 14783 eligible subjects with acute stroke were initially extracted in this database. According to exclusion criteria, a total of 3436 subjects were excluded. Finally, 11347 subjects were enrolled in this study. Fig. 1 showed flow chart describing exclusion and inclusion criteria for selection of data.

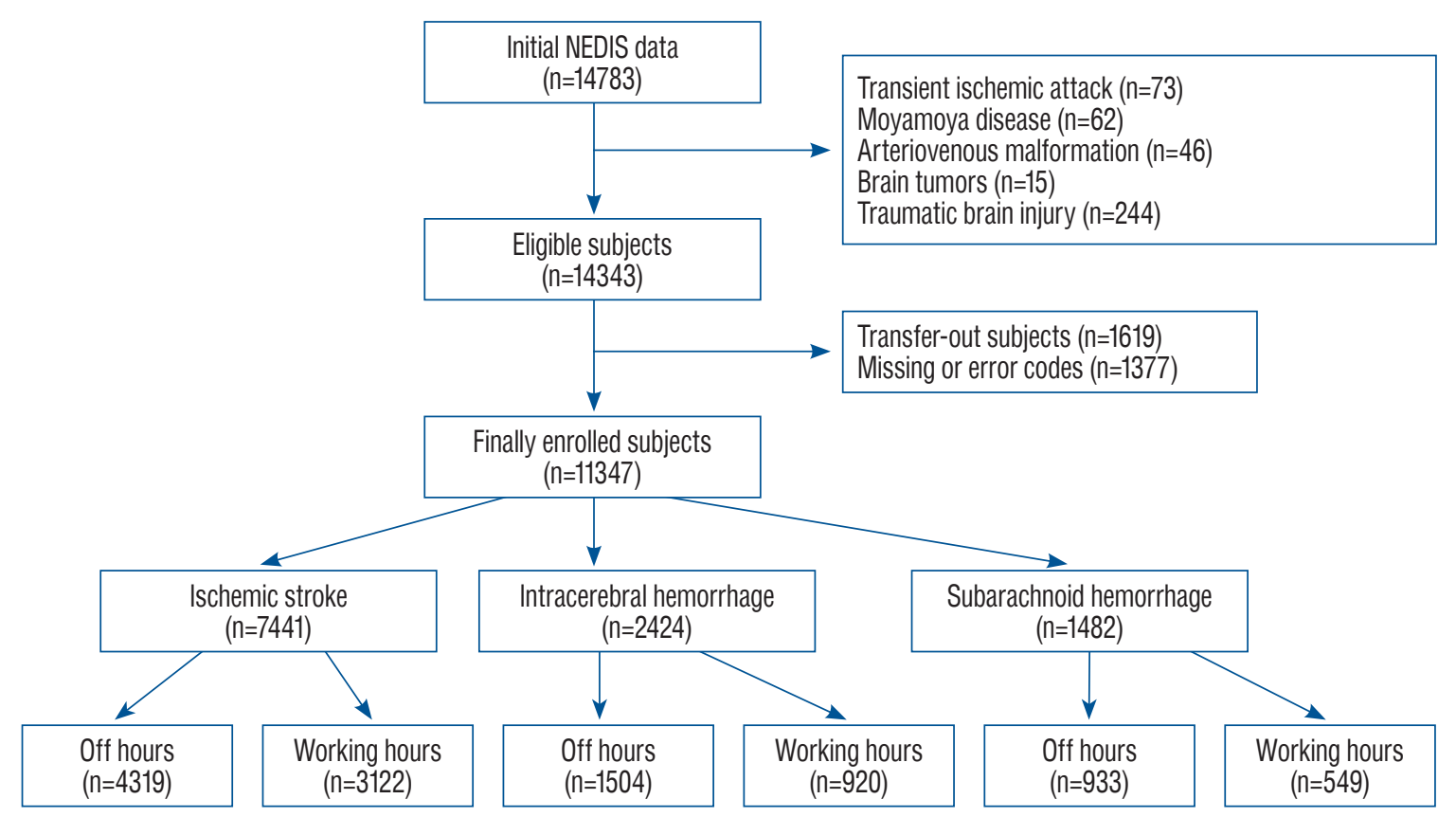

Fig. 1. Inclusion and exclusion criteria for selection of data. NEDIS : National Emergency Department Information System. 


\section{Study designs}

We respectively analyzed finally enrolled data of 11347 subjects with acute stroke in Korea. "Working-hour hospital presentation", "working-hour admission" or "working hours" were defined as the subjects presented to hospital emergency center between 8:00 AM to 6:00 PM on any weekday in regular working hours. "Off-hour hospital presentation", "off-hour admission" or "off hours" were defined as the subjects admitted at any other time before or after working hours. Weekends and public holidays were also included in off hours in this study. The primary outcome measure was in-hospital mortality of acute stroke. The secondary outcome measures were "not discharge to home", unfavorable outcome, severe disability, 7-day mortality and 30-day mortality. Glasgow coma scale (GCS) scores were used to evaluate neurological status of all subjects. "Not discharge to home" means transfer to other hospitals or death. "Unfavorable outcome" means transfer to other hospitals or hopeless discharge or death. "Severe disability" means motor weakness, grade 1, 2 or death at discharge.

\section{Statistical analysis}

Statistical analysis was performed using SPSS ver. 15.0 (SPSS
Inc., Chicago, IL, USA). Independent student t-test for continuous variables, chi-square test or Fisher's exact test for nominal variables and Mann-Whitney $U$ test for non-parametric variables were used. Multivariate models were generated by binary logistic regression model or Cox's proportional hazard model, which were adjusted for age, gender, GCS score, systolic blood pressure, pulse rate, craniotomy or craniectomy, thrombolysis (IS), extraventricular drainage (ICH, SAH), hematoma aspiration ( $\mathrm{ICH}$ ), endovascular coiling (SAH). Odds ratio (OR) for unfavorable outcome, hazard ratio (HR) for 7-day mortality, 30-day mortality and in-hospital mortality and 95\% confidence interval (CI) were used. All $p$-values $\leq 0.05$ were considered as "statistically significant".

\section{RESULTS}

Of the 11347 stroke subjects included, off-hour hospital presentation was more frequent than working hours $(59.5 \%$ vs. $40.5 \%) ; 4319(58.0 \%)$ in IS, $1504(62.0 \%)$ in ICH, and 933 $(63.0 \%)$ in SAH, respectively. Table 1 shows baseline data of 11347 stroke subjects according to subtypes from 26 hospitals

Table 1. Baseline data of 11347 stroke subjects from 26 hospitals of wide regional or regional emergency medical centers in Korea

\begin{tabular}{|c|c|c|c|c|c|c|c|c|c|}
\hline & \multicolumn{3}{|c|}{ IS } & \multicolumn{3}{|c|}{$\mathrm{ICH}$} & \multicolumn{3}{|c|}{ SAH } \\
\hline & $\begin{array}{l}\text { Off hours } \\
(n=4319)\end{array}$ & $\begin{array}{l}\text { Working } \\
\text { hours } \\
(n=3122)\end{array}$ & $p$-value & $\begin{array}{l}\text { Off hours } \\
(n=1504)\end{array}$ & $\begin{array}{l}\text { Working } \\
\text { hours } \\
(n=920)\end{array}$ & $p$-value & $\begin{array}{l}\text { Off hours } \\
(n=933)\end{array}$ & $\begin{array}{l}\text { Working } \\
\text { hours } \\
(n=549)\end{array}$ & $p$-value \\
\hline Age (years) & $68.0 \pm 12.4$ & $68.6 \pm 12.0$ & 0.032 & $62.6 \pm 13.7$ & $62.9 \pm 13.6$ & 0.602 & $56.7 \pm 13.2$ & $58.2 \pm 13.7$ & 0.059 \\
\hline Male & $2399(55.5)$ & $1793(57.3)$ & 0.101 & 768 (51.1) & $496(53.9)$ & 0.173 & $340(36.4)$ & 196 (35.7) & 0.775 \\
\hline Female & $1921(44.5)$ & $1329(42.6)$ & & $736(48.9)$ & $424(46.1)$ & & $593(63.6)$ & $353(64.3)$ & \\
\hline \multicolumn{10}{|l|}{ Medical history } \\
\hline Hypertension & $2518(58.3)$ & $1813(58.1)$ & 0.843 & $768(51.1)$ & $423(46.0)$ & 0.015 & 354 (37.9) & $198(36.1)$ & 0.471 \\
\hline Diabetes & $1050(24.3)$ & 814 (26.1) & 0.083 & 235 (15.6) & $140(14.6)$ & 0.594 & $64(6.9)$ & $40(7.3)$ & 0.756 \\
\hline Heart diseases & $741(17.2)$ & $529(16.9)$ & 0.810 & $104(6.9)$ & $39(4.2)$ & 0.007 & $27(2.9)$ & $24(4.4)$ & 0.132 \\
\hline CVA & $724(16.8)$ & $485(15.5)$ & 0.156 & $205(13.6)$ & $112(12.2)$ & 0.302 & $47(5.0)$ & $27(4.9)$ & 0.919 \\
\hline \multicolumn{10}{|l|}{ Admission routs } \\
\hline Direct ER & $2917(67.5)$ & $1981(63.5)$ & $<0.001$ & $868(57.7)$ & $530(57.6)$ & 0.017 & $373(40.0)$ & $223(40.6)$ & 0.119 \\
\hline $\begin{array}{l}\text { Transfer from other } \\
\text { hospitals }\end{array}$ & 1378 (31.9) & 1019 (32.6) & & $633(42.1)$ & $381(41.4)$ & & $557(59.7)$ & $320(58.3)$ & \\
\hline Refer from OPD & $20(0.5)$ & 118 (3.8) & & $2(0.1)$ & $9(1.0)$ & & $2(0.2)$ & $6(1.1)$ & \\
\hline Others & $4(0.1)$ & $4(0.1)$ & & $1(0.1)$ & $0(0.0)$ & & $1(0.1)$ & $0(0.0)$ & \\
\hline
\end{tabular}

Values are presented as mean \pm standard deviation or number (\%). IS : ischemic stroke, ICH : intracerebral hemorrhage, SAH : subarachnoid hemorrhage, CVA : cerebrovascular accident, ER : emergency department, OPD : outpatient department 
of wide regional or regional emergency medical centers in Korea.

In patients with IS, off-hour hospital presentation had significantly more elderly patients $\geq 65$ years (35.4\% off hours vs. $32.1 \%$ working hours, $p=0.029$ ) and significantly more frequent intensive care unit (ICU) admission (32.5\% off hours vs. $29.9 \%$ working hours, $p=0.017$ ) than in working hours. However, we could not observe delay by time to emergency room (ER), inter-hospital transfer and ER stay in patients with off-hour admission. There were also no significant differences between off hours and working hours in other medications or treatments including anti-platelets (74.0\% off hours vs. $73.2 \%$ working hours, $p=0.443$ ), anti-coagulants ( $28.7 \%$ off hours vs. $27.1 \%$ working hours, $p=0.132)$, vessel recanalization $(14.5 \%$ off hours vs. $14.1 \%$ working hours, $p=0.675$ ) and decompressive surgery. In patients with off-hour admission, we did not detect meaningful abandonment of treatment $(2.5 \%$ off hours vs. $2.4 \%$ working hours, $p=0.807$ ) or significant contraindication of vessel recanalization including risk of hemorrhage (3.4\% off hours vs. $3.3 \%$ working hours, $p=0.822$ ), bleeding tendency (2.2\% off hours vs. $1.8 \%$ working hours, $p=0.261)$ and uncontrolled hypertension $(0.7 \%$ off hours vs. $0.5 \%$ working hours, $p=0.240$ ). In patients admitted with ICH, offhour hospital presentation had significantly lower GCS scores (13 off hours vs. 14 working hours, $p=0.024$ ) than those in working hours. However, we did not discover significant differences between off hours and working hours in surgical procedures including hematoma aspiration (9.3\% off hours vs. $8.9 \%$ working-hours, $p=0.743)$, extra-ventricular drainage (17.5\% off hours vs. $16.1 \%$ working hours, $p=0.373)$ and decompressive surgery. In subjects with SAH, off-hour admission had significantly longer ER stay (5.0 hours off hours vs.

Table 2. Clinical characteristics of off-hour hospital presentation in different subtypes of acute stroke

\begin{tabular}{|c|c|c|c|c|c|c|c|c|c|}
\hline & \multicolumn{3}{|c|}{ IS } & \multicolumn{3}{|c|}{$\mathrm{ICH}$} & \multicolumn{3}{|c|}{ SAH } \\
\hline & $\begin{array}{l}\text { Off hours } \\
(n=4319)\end{array}$ & $\begin{array}{l}\text { Working } \\
\text { hours } \\
(n=3122)\end{array}$ & $p$-value & $\begin{array}{l}\text { Off hours } \\
(n=1504)\end{array}$ & $\begin{array}{l}\text { Working } \\
\text { hours } \\
(n=920)\end{array}$ & $p$-value & $\begin{array}{l}\text { Off hours } \\
(n=933)\end{array}$ & $\begin{array}{l}\text { Working } \\
\text { hours } \\
(n=549)\end{array}$ & $p$-value \\
\hline Age, $\geq 65$ years & $1492(35.4)$ & $1003(32.1)$ & 0.029 & $789(52.5)$ & $478(52.0)$ & 0.810 & $657(70.4)$ & $373(67.9)$ & 0.317 \\
\hline Time to ER (hours) & $1.0 \pm 1.0$ & $2.7 \pm 0.9$ & 0.218 & $3.6 \pm 5.0$ & $4.2 \pm 6.0$ & 0.003 & $1.0 \pm 39.0$ & $2.0 \pm 43.5$ & 0.637 \\
\hline $\begin{array}{l}\text { Transfer from other } \\
\text { hospitals }\end{array}$ & $1378(31.9)$ & 1019 (32.6) & 0.504 & $633(42.1)$ & $381(41.4)$ & 0.744 & $557(59.7)$ & $320(58.3)$ & 0.593 \\
\hline ER stay (hours) & $5.8 \pm 17.7$ & $6.0 \pm 7.0$ & 0.672 & $5.4 \pm 8.1$ & $4.9 \pm 9.1$ & 0.124 & $557 \pm 59.7$ & $320 \pm 58.3$ & 0.593 \\
\hline Systolic BP (mmHg) & $152.2 \pm 29.7$ & $150.3 \pm 28.8$ & 0.004 & $166.9 \pm 37.4$ & $165.4 \pm 35.4$ & 0.326 & $149.7 \pm 41.2$ & $149.4 \pm 38.1$ & 0.883 \\
\hline Pulse rate (beats/m) & $79.9 \pm 20.4$ & $79.2 \pm 21.7$ & 0.186 & $81.9 \pm 18.2$ & $82.1 \pm 17.2$ & 0.803 & $79.8 \pm 20.4$ & $79.6 \pm 19.3$ & 0.862 \\
\hline Motor weakness & $1726(40.0)$ & $1264(40.5)$ & 0.649 & $676(44.9)$ & $404(43.9)$ & 0.619 & $57(6.1)$ & $40(7.3)$ & 0.376 \\
\hline \multicolumn{10}{|l|}{ Consciousness levels } \\
\hline Alert & $3263(75.5)$ & $2374(76.0)$ & 0.442 & $653(44.3)$ & $427(46.4)$ & 0.184 & $485(52.0)$ & $296(53.9)$ & 0.414 \\
\hline Verbal response & $689(16.0)$ & 499 (16.0) & & $369(24.5)$ & $333(25.3)$ & & $156(16.7)$ & $100(18.2)$ & \\
\hline Painful response & $335(7.8)$ & $235(7.5)$ & & $373(24.8)$ & $209(22.7)$ & & $181(19.4)$ & $88(16.0)$ & \\
\hline Unresponsive & $32(0.7)$ & $14(0.4)$ & & $109(7.2)$ & $51(5.5)$ & & $111(11.9)$ & 65 (11.8) & \\
\hline GCS, median $(\mathrm{Q} 1, \mathrm{Q} 3)$ & $15(14,15)$ & $15(14,15)$ & 0.609 & $13(8,15)$ & $14(9,15)$ & 0.024 & $14(8,15)$ & $14(9,15)$ & 0.217 \\
\hline $\mathrm{GCS} \leq 8$ & $275(6.4)$ & $188(6.0)$ & 0.543 & $420(27.9)$ & $222(24.1)$ & 0.040 & $259(27.8)$ & $136(24.8)$ & 0.209 \\
\hline CT scan & $3100(71.8)$ & $2174(69.6)$ & 0.045 & $1331(88.5)$ & $806(87.6)$ & 0.511 & $820(87.9)$ & $480(87.4)$ & 0.796 \\
\hline MRI scan & $3633(84.1)$ & $2567(82.2)$ & 0.031 & $155(10.3)$ & $123(13.4)$ & 0.022 & $82(8.8)$ & $52(9.5)$ & 0.658 \\
\hline Admission to ICU & $1403(32.5)$ & $933(29.9)$ & 0.017 & $559(37.2)$ & $380(41.3)$ & 0.042 & $867(92.9)$ & $501(91.3)$ & 0.244 \\
\hline Decompressive surgery & $59(1.4)$ & $35(1.1)$ & 0.350 & $195(13.0)$ & 135 (13.7) & 0.234 & $320(34.3)$ & $182(33.2)$ & 0.652 \\
\hline
\end{tabular}

Values are presented as mean \pm standard deviation or number (\%) unless otherwise indicated. IS : ischemic stroke, ICH : intracerebral hemorrhage, SAH : subarachnoid hemorrhage, ER : emergency room, BP : blood pressure, GCS : Glasgow coma scale score, CT : computed tomography, MRI : magnetic resonance imaging, ICU : intensive care unit 
4.4 hours working hours, $p=0.038$ ) than that in working hours. However, there were no significant differences between off hours and working hours in endovascular coiling $(42.8 \%$ off hours vs. $46.1 \%$ working hours, $p=0.214)$, surgical clipping (34.3\% off hours vs. $33.2 \%$ working hours, $p=0.652$ ), extraventricular drainage (18.8\% off hours vs. $15.5 \%$ working

Table 3. Clinical outcomes of off-hour hospital presentation in different subtypes of acute stroke

\begin{tabular}{|c|c|c|c|c|c|c|c|c|c|}
\hline & \multicolumn{3}{|c|}{ IS } & \multicolumn{3}{|c|}{$\mathrm{ICH}$} & \multicolumn{3}{|c|}{ SAH } \\
\hline & $\begin{array}{l}\text { Off hours } \\
(n=4319)\end{array}$ & $\begin{array}{l}\text { Working } \\
\text { hours } \\
(n=3122)\end{array}$ & $p$-value & $\begin{array}{l}\text { Off hours } \\
(n=1504)\end{array}$ & $\begin{array}{l}\text { Working } \\
\text { hours } \\
(n=920)\end{array}$ & $p$-value & $\begin{array}{l}\text { Off hours } \\
(n=933)\end{array}$ & $\begin{array}{l}\text { Working } \\
\text { hours } \\
(n=549)\end{array}$ & $p$-value \\
\hline \multicolumn{10}{|l|}{ Discharge outcomes } \\
\hline Normal discharge & $3127(72.4)$ & $2389(76.5)$ & 0.004 & $748(49.7)$ & $485(52.7)$ & 0.431 & $565(60.6)$ & $324(59.0)$ & 0.394 \\
\hline Transfer to other hospitals & $828(19.2)$ & $529(16.9)$ & & $438(29.1)$ & $257(27.9)$ & & $135(14.5)$ & $100(18.2)$ & \\
\hline Hopeless discharge & $4(0.1)$ & $4(0.1)$ & & $8(0.5)$ & $1(0.1)$ & & $4(0.4)$ & $2(0.4)$ & \\
\hline Self-discharge & $97(2.2)$ & $59(1.9)$ & & $34(2.3)$ & $19(2.1)$ & & $18(1.9)$ & $12(2.2)$ & \\
\hline In-hospital mortality & $230(5.3)$ & $121(3.9)$ & 0.004 & $263(17.5)$ & $148(16.1)$ & 0.373 & $203(21.8)$ & $109(19.9)$ & 0.385 \\
\hline Hospital stay (days) & $15.8 \pm 23.0$ & $16.0 \pm 23.9$ & 0.649 & $29.4 \pm 36.6$ & $30.9 \pm 40.0$ & 0.345 & $31.9 \pm 40.7$ & $30.8 \pm 35.8$ & 0.595 \\
\hline Not discharged to home ${ }^{*}$ & $1058(24.5)$ & $650(20.8)$ & $<0.001$ & $701(46.6)$ & $405(44.6)$ & 0.215 & $338(36.2)$ & $209(38.1)$ & 0.478 \\
\hline Unfavorable outcomes $^{\dagger}$ & $1062(24.6)$ & $654(20.9)$ & $<0.001$ & $709(47.1)$ & $406(44.1)$ & 0.149 & $342(36.7)$ & $211(38.4)$ & 0.494 \\
\hline Severe disability ${ }^{\ddagger}$ & $1203(27.9)$ & $808(25.9)$ & 0.059 & $809(53.8)$ & $481(52.3)$ & 0.470 & $418(44.8)$ & $229(41.7)$ & 0.247 \\
\hline 7-day mortality & $135(3.1)$ & $80(2.6)$ & 0.152 & $148(9.8)$ & $69(7.5)$ & 0.050 & $97(10.4)$ & $50(9.1)$ & 0.423 \\
\hline 30-day mortality & $208(4.8)$ & $111(3.6)$ & 0.008 & $245(16.3)$ & $134(14.6)$ & 0.257 & $194(20.8)$ & 98 (17.9) & 0.169 \\
\hline
\end{tabular}

Values are presented as mean \pm standard deviation or number (\%). *Not discharge to home means transfer to other hospitals or death. ${ }^{\dagger}$ Unfavorable outcomes means transfer to other hospitals, hopeless discharge or death. ${ }^{\ddagger}$ Severe disability means motor weakness, grade 1, 2 or death at discharge. IS: ischemic stroke, $\mathrm{ICH}$ : intracerebral hemorrhage, $\mathrm{SAH}$ : subarachnoid hemorrhage

Table 4. Unadjusted and adjusted odds ratios or hazard ratios of off-hour admission in different subtypes of acute stroke

\begin{tabular}{|c|c|c|c|}
\hline & IS & $\mathrm{ICH}$ & SAH \\
\hline \multicolumn{4}{|c|}{ Unfavorable outcomes* } \\
\hline Unadjusted & $1.230(1.102-1.374)^{\dagger}$ & 1.129 (0.957-1.331) & $1.079(0.868-1.341)$ \\
\hline Adjusted & $1.244(1.106-1.400)^{\dagger}$ & $1.070(0.894-1.280)$ & $1.199(0.927-1.553)$ \\
\hline \multicolumn{4}{|l|}{ 7-day mortality } \\
\hline Unadjusted & $1.246(0.945-1.643)$ & 1.326 (0.996-1.764) & $1.142(0.812-1.607)$ \\
\hline Adjusted & $1.210(0.917-1.596)$ & $1.128(0.846-1.504)$ & $1.094(0.772-1.550)$ \\
\hline \multicolumn{4}{|c|}{ 30-day mortality } \\
\hline Unadjusted & $1.365(1.084-1.719)^{\dagger}$ & $1.140(0.923-1.407)$ & $1.172(0.918-1.493)$ \\
\hline Adjusted & $1.359(1.079-1.712)^{\dagger}$ & 1.504 (0.853-1.302) & $1.200(0.938-1.536)$ \\
\hline \multicolumn{4}{|c|}{ In-hospital mortality } \\
\hline Unadjusted & $1.391(1.116-1.733)^{\dagger}$ & 1.111 (0.908-1.359) & $1.098(0.870-1.386$ \\
\hline Adjusted & $1.402(1.124-1.747)^{\dagger}$ & $1.042(0.851-0.276)$ & $1.133(0.895-1.436)$ \\
\hline
\end{tabular}

Values are presented as odds ratio (or hazard ratio) (95\% confidence interval). Multivariate models were generated by binary logistic regression model for unfavorable outcome and Cox proportional hazard model for 7-day mortality, 30-day mortality, in-hospital mortality and were adjusted for age, gender, Glasgow coma scale score, systolic blood pressure, pulse rate, craniotomy or craniectomy, intravenous or intra-arterial thrombolysis (IS), extraventricular drainage $(\mathrm{ICH}, \mathrm{SAH})$, hematoma aspiration $(\mathrm{ICH})$, endovascular coiling $(\mathrm{SAH})$. ${ }^{*}$ Unfavorable outcomes means transfer to other hospitals, hopeless discharge and in-hospital mortality. ${ }^{\dagger} p$-value $<0.05$. IS : ischemic stroke, ICH : intracerebral hemorrhage, SAH : subarachnoid hemorrhage 
hours, $p=0.156$ ) and decompressive surgery. Table 2 shows clinical characteristics of off-hour hospital presentation in different subtypes of acute stroke.

Overall in-hospital mortality of acute stroke was 1074 (9.5\%). Those of subtypes of stroke were 351 (4.7\%) for IS, 448 (17.6\%) for ICH, and 370 (23.3\%) for SAH. Overall in-hospital mortality of acute stroke in patients with off-hour admission was significantly higher than that in working hours $(10.3 \%$ off hours vs. $8.2 \%$ working hours, $p<0.001)$. In patients admitted with IS, off-hour hospital presentation resulted in significantly more frequent unfavorable outcome, not discharge to home, 30-day mortality and in-hospital mortality than those in working hours, but not in subjects with ICH and SAH. Table 3 shows clinical outcomes of off-hour hospital presentation in different subtypes of acute stroke.

In patients with IS, off-hour admission was associated with unfavorable outcome (OR, 1.244; 95\% CI, 1.106-1.400), 30day mortality (HR, 1.359; 95\% CI, 1.079-1.712) and in-hospital mortality (HR, 1.402; 95\% CI, 1.124-1.747) even after adjustment for compounding risk factors. Off-hour hospital presentation increased death at discharge by about $40 \%$ in patients with IS. However, off-hour admission was not related to worse outcomes in subjects with ICH and SAH. Table 4 shows unadjusted and adjusted OR or HR of off-hour hospital presentation in different subtypes of acute stroke.

\section{DISCUSSION}

This study demonstrated that off-hour hospital presentation was associated with increased short-term morbidity and mortality in patients with IS in Korea and death at discharge was increased by about $40 \%$ in off hours than in working hours, but that was not related to poor outcome in subjects with ICH and SAH. Also, off-hour admission had more elderly and more frequent ICU admission than working hours.

Several observational studies have assessed the 'off-hour effect' in patients with IS. Prior studies have reported incoherent results on whether off-hour admission is associated with worse outcome after IS $\mathrm{I}^{5,22,24,28)}$ or not $\mathrm{t}^{4,10,13,15,19,27,29)}$. In a retrospective study of 26676 IS subjects from the Hospital Morbidity Database of 606 hospitals in Canada, Saposnik et al. ${ }^{25)}$ reported that weekend admission was associated with early mortality, which was similarly observed among subjects pre- sented to urban versus rural medical centers or specialist versus a general practitioner. Similarly, in the analysis of the Get With The Guidelines (GWTG)-Stroke program data of 187669 IS patients from 857 hospitals in America, Reeves et al. ${ }^{24)}$ showed that off-hour hospital presentation was associated with increased mortality, but the effect was very small. Since then, a retrospective cohort study of 82219 IS patients from 115 Dutch hospitals reported that weekend admission was related to an increase of 7-day mortality for IS patients, which is due to an underlying off-hour risk present during the week days ${ }^{22}$. A prospective database of Stroke Improvement National Audit Programme of 45726 stroke subjects of 130 hospitals in England, Campbell et al. ${ }^{4)}$ reported that weekend hospital presentation was associated with higher 30-day mortality. They suggested that unevenness in the use of stroke management during working hours as well as during off hours was common in contemporary England, but the impact on mortality is small and largely due to higher disease severity in patients presented during off hours. Recently, Korean nationwide claims data of 8957 IS subjects revealed that weekend admission was significantly associated with higher 30-day mortality ${ }^{5}$.

On contrary, a retrospective cohort study of 51643 prospective data from 23 ICUs in the Paris metropolitan area disclosed that off-hour presentation was not related to higher death rate $^{18)}$. A study of the Nationwide Inpatient Sample (NIS) Database of 599087 IS patients showed that there is a slight off-hour effect on thrombolysis and length of stay, but no association with higher mortality ${ }^{10)}$. A Korean study of 7075 IS patients of tertiary hospitals from the Clinical Research Center for Stroke registry-5 reported that off-hour admission was not associated with an unfavorable 3-month functional outcome and off-hour effect might be controlled with well-organized stroke management strategies ${ }^{15}$.

These discrepancies across previous studies might be resulted from differences in the health care system including the availability of specialized stroke units ${ }^{4,25}$, and the number of stroke physician ${ }^{28)}$ during off-hour time. On the other hand, Nationwide Survey of Acute Stroke Care Capacity for Proper Designation of Comprehensive Stroke Center in Japan study of 35685 subjects from 262 hospitals for IS, ICH, or SAH reported that the effects of off-hour presentation were disappeared after adjustment for consciousness level on admission ${ }^{13)}$. They suggested that well-known off-hour effect might 
be attributed to the severely ill patient population during off hours. However, in this study, off-hour hospital presentation had significant impact on short-term mortality in patients with IS even after adjusting for outcome co-variates including consciousness level. Like most previous studies ${ }^{2,9,14,31)}$, we revealed no significant differences on clinical outcomes of IS going through delay of hospital presentation and treatment delay for intravenous or intra-arterial thrombolysis or surgery during ER stay between off hours and working hours. However, in this study, age $\geq 65$ years and ICU admission after IS were even higher during off hours. This data implies that worse outcome might be attributed to old age or the severity of other medical illness apart from the severity of stroke during off hours in patients presented with IS.

Among the previous studies of ICH, early two studies of a retrospective cohort study of 13821 subjects of NIS ${ }^{7)}$ and analysis of the GWTG-Stroke program data of 34845 acute hemorrhagic stroke ${ }^{24)}$ showed the association between off-hour hospital presentation and higher short-term mortality, but most of studies have ever reported no off-hour effect in patients with $\mathrm{ICH}^{6,20,21,26,32)}$. The Intensive Blood Pressure Reduction in Acute Cerebral Hemorrhage Trial of 2794 subjects disclosed off-hour hospital presentation was not related to higher mortality or morbidity in subjects with acute $\mathrm{ICH}^{26)}$. Strict blood pressure control can give rise to similar therapeutic effect irrespective of admission hours ${ }^{26,30)}$. Furthermore, a recent study from the Universitätsklinikum Erlangen Cohort of Patients With Spontaneous Intracerebral Hemorrhage registry of 1269 subjects suggested an off-hour effect in ICH is associated with functional outcome rather than death rate ${ }^{21)}$. In this study, 7-day mortality was significantly higher in off hours than in working hours, but it disappeared after adjustment of compounding variables. Like most of prior studies, we could not detect an association between off-hour hospital presentation and clinical outcomes although the subjects admitted with ICH had even higher severe neurological deficit and more ICU admission during off hours.

The previous studies of SAH, the other constituents of hemorrhagic stroke, have yielded inconsistent findings on the impact of off-hour hospital presentation on clinical outcomes. Most of early previous studies have reported no association between off-hour hospital presentation and worse outcome in patients with $\mathrm{SAH}^{6,23,32)}$. However, recent two studies of SAH suggested a relationship between off-hour hospital presenta- tion and worse outcome in patients with SAH. A prospective study of 285 aneurysmal SAH from 12 large regional hospitals of the northwest of England reported higher short-term mortality of subjects with SAH, but there were no off-hour effects on long-term mortality ${ }^{8)}$. Another retrospective cohort data of 54703 SAH from NIS ${ }^{12)}$ showed higher in-hospital mortality in SAH patients with weekend hospital presentation. In this study, there were no significant differences in clinical characteristics, severity of disease and treatments of SAH between off hours and working hours. We did not find an association between off-hour hospital presentation and clinical outcomes in subjects with SAH.

This study has several limitations. First, NEDIS data covers only non-capital area of Korea excluding a metropolitan area of Seoul-Incheon-Gyeonggi districts. Hence, the mortality of acute stroke could be overestimated due to greater quality level and accessibility of emergency medical centers of SeoulIncheon-Gyeonggi districts. Second, this NEDIS data is somewhat out of date and may be different from current medical conditions. Third, NEDIS database has some limited data on different diseases of acute stroke. It has no contents of National Institutes of Health Stroke Scale, individual subjects' treatment, complications and causes of death. This limited information made it difficult for us to find an accurate cause about why this results occur.

\section{CONCLUSION}

This study suggests that off-hour hospital presentation may be associated with poor short-term morbidity and mortality in patients with IS, but that is not likely to be related to poor outcome in subjects with ICH and SAH. Excessive death seems to be attributed to old age or the higher severity of medical illnesses apart from that of stroke of patients admitted during off hours. Multidisciplinary management for elderly or frequent medical illnesses during off hours is important to improve clinical outcome of acute stroke. Further multicenter prospective study is required to investigate a relationship between off-hour hospital presentation and longterm outcome in patients with acute stroke. 


\section{CONFLICTS OF INTEREST}

No potential conflict of interest relevant to this article was reported.

\section{INFORMED CONSENT}

This type of study does not require informed consent.

\section{AUTHOR CONTRIBUTIONS}

\author{
Conceptualization : TK, CJ \\ Data curation : CJ \\ Formal analysis : TK, CJ \\ Methodology : TK, CJ \\ Project administration : CJ \\ Visualization: CJ, TK \\ Writing - original draft : TK \\ Writing - review \& editing: CJ
}

\section{ORCID}

Taikwan Kim https://orcid.org/0000-0002-3862-181X

Cheolsu Jwa

\section{- Acknowledgements}

The authors thank Dr. Han Deok Yoon and the personnels of National Emergency Medical Center who provided the data of National Emergency Department Information System on cerebrovascular diseases.

This research was based on the data of National Emergency Department Information System.

\section{References}

1. Bendavid E, Kaganova Y, Needleman J, Gruenberg L, Weissman JS : Complication rates on weekends and weekdays in US hospitals. Am J Med 120 : 422-428, 2007

2. Bodenant $M$, Leys $D$, Debette $S$, Cordonnier $C$, Dumont $F$, Hénon $H$, et al. : Intravenous thrombolysis for acute cerebral ischaemia: comparison

of outcomes between patients treated at working versus nonworking hours. Cerebrovasc Dis 30 : 148-156, 2010

3. Buckley D, Bulger D : Trends and weekly and seasonal cycles in the rate of errors in the clinical management of hospitalized patients. Chronobiol Int 29 : 947-954, 2012

4. Campbell JT, Bray BD, Hoffman AM, Kavanagh SJ, Rudd AG, Tyrrell PJ, et al. : The effect of out of hours presentation with acute stroke on processes of care and outcomes: analysis of data from the Stroke Improvement National Audit Programme (SINAP). PLoS One 9 : e87946, 2014

5. Cho KH, Park EC, Nam CM, Choi Y, Shin J, Lee SG : Effect of weekend admission on in-hospital mortality in patients with ischemic stroke: an analysis of Korean nationwide claims data from 2002 to 2013. J Stroke Cerebrovasc Dis 25 : 419-427, 2016

6. Crowley RW, Yeoh HK, Stukenborg GJ, Ionescu AA, Kassell NF, Dumont AS : Influence of weekend versus weekday hospital admission on mortality following subarachnoid hemorrhage. J Neurosurg $111:$ 60-66, 2009

7. Crowley RW, Yeoh HK, Stukenborg GJ, Medel R, Kassell NF, Dumont AS : Influence of weekend hospital admission on short-term mortality after intracerebral hemorrhage. Stroke 40 : 2387-2392, 2009

8. Deshmukh H, Hinkley M, Dulhanty L, Patel HC, Galea JP : Effect of weekend admission on in-hospital mortality and functional outcomes for patients with acute subarachnoid haemorrhage (SAH). Acta Neurochir (Wien) $158:$ 829-835, 2016

9. Haeusler KG, Gerischer LM, Vatankhah B, Audebert HJ, Nolte CH : Impact of hospital admission during nonworking hours on patient outcomes after thrombolysis for stroke. Stroke 42 : 2521-2525, 2011

10. Hoh BL, Chi YY, Waters MF, Mocco J, Barker FG 2nd : Effect of weekend compared with weekday stroke admission on thrombolytic use, inhospital mortality, discharge disposition, hospital charges, and length of stay in the nationwide inpatient sample database, 2002 to 2007. Stroke 41 : 2323-2328, 2010

11. Johnson $\mathrm{J}$ : The increased incidence of anesthetic adverse events in late afternoon surgeries. AORN J $88:$ 79-87, 2008

12. Johnson WC, Morton-Gonzaba NA, Lacci JV, Godoy D, Mirahmadizadeh A, Seifi A : Re-evaluating the weekend effect on SAH: a nationwide analysis of the association between mortality and weekend admission. Neurocrit Care 30 : 293-300, 2019

13. Kamitani S, Nishimura K, Nakamura F, Kada A, Nakagawara J, Toyoda K, et al. : Consciousness level and off-hour admission affect discharge outcome of acute stroke patients: a J-ASPECT study. J Am Heart Assoc 3 : e001059, 2014

14. Karliński M, Kobayashi A, Sobolewski P, Lisewski P, Romanowicz S, Fryze $W$, et al. : Is there a bad time for intravenous thrombolysis? The experience of polish stroke centers. Neurol Neurochir Pol 48 : 45-51, 2014

15. Kim C, Jang MU, Oh MS, Park JH, Jung S, Lee JH, et al. : Off-hour effect on 3-month functional outcome after acute ischemic stroke: a prospective multicenter registry. PLoS One 9 : e105799, 2014

16. Kostis WJ, Demissie K, Marcella SW, Shao YH, Wilson AC, Moreyra AE, et al. : Weekend versus weekday admission and mortality from myocar- 
dial infarction. N Engl J Med 356 : 1099-1109, 2007

17. Löwhagen Hendén P, Rentzos A, Karlsson JE, Rosengren L, Oras J, Ricksten SE : Off-hour admission and impact on neurological outcome in endovascular treatment for acute ischemic stroke. Acta Anaesthesiol Scand $63: 208-214,2019$

18. Luyt CE, Combes A, Aegerter P, Guidet B, Trouillet JL, Gibert C, et al. : Mortality among patients admitted to intensive care units during weekday day shifts compared with "off" hours. Crit Care Med 35 : 3-11, 2007

19. Martínez-Martínez MM, Fernández-Travieso J, Fuentes B, Ruiz-Ares $G$, Martínez-Sánchez P, Cazorla García R, et al. : Off-hour effects on stroke care and outcome in stroke centres. Eur J Neurol 19 : 1140-1145, 2012

20. McDowell MM, Kellner CP, Sussman ES, Bruce SS, Bruce RA, Heuts SG, et al. : The role of admission timing in the outcome of intracerebral hemorrhage patients at a specialized stroke center. Neurol Res 36 : 95101, 2014

21. Mrochen A, Sprügel MI, Gerner ST, Madžar D, Kuramatsu JB, Hoelter $P$, et al. : Invasiveness and clinical outcomes of off-hour admissions in patients with intracerebral hemorrhage. J Stroke Cerebrovasc Dis 29 : 104505, 2020

22. Ogbu UC, Westert GP, Slobbe LC, Stronks K, Arah OA : A multifaceted look at time of admission and its impact on case-fatality among a cohort of ischaemic stroke patients. J Neurol Neurosurg Psychiatry $82: 8-13,2011$

23. Pandey AS, Wilkinson DA, Gemmete JJ, Chaudhary N, Thompson BG, Burke JF : Impact of weekend presentation on short-term outcomes and choice of clipping vs coiling in subarachnoid hemorrhage. Neurosurgery $81: 87-91,2017$
24. Reeves MJ, Smith E, Fonarow G, Hernandez A, Pan W, Schwamm LH, et al. : Off-hour admission and in-hospital stroke case fatality in the get with the guidelines-stroke program. Stroke $40: 569-576,2009$

25. Saposnik G, Baibergenova A, Bayer N, Hachinski V : Weekends: a dangerous time for having a stroke? Stroke 38 : 1211-1215, 2007

26. Sato S, Arima H, Heeley E, Hirakawa Y, Delcourt C, Lindley RI, et al. : Off-hour admission and outcomes in patients with acute intracerebral hemorrhage in the INTERACT2 trial. Cerebrovasc Dis 40 : 114-120, 2015

27. Streifler JY, Benderly M, Molshatzki N, Bornstein N, Tanne D : Off-hours admission for acute stroke is not associated with worse outcome--a nationwide Israeli stroke project. Eur J Neurol 19 : 643-647, 2012

28. Tung YC, Chang GM, Chen YH : Associations of physician volume and weekend admissions with ischemic stroke outcome in Taiwan: a nationwide population-based study. Med Care 47 : 1018-1025, 2009

29. Wang G, Liu G, Zhang R, Ji R, Gao B, Wang Y, et al. : Evaluation of offhour emergency care in acute ischemic stroke: results from the china national stroke registry. PLoS One 10 : e0138046, 2015

30. Wang X, Arima H, Heeley E, Delcourt C, Huang Y, Wang J, et al. : Magnitude of blood pressure reduction and clinical outcomes in acute intracerebral hemorrhage: intensive blood pressure reduction in acute cerebral hemorrhage trial study. Hypertension 65 : 1026-1032, 2015

31. Wei XE, Zhao YW, Lu J, Li MH, Li WB, Zhou YJ, et al. : Timing of recanalization and outcome in ischemic-stroke patients treated with recombinant tissue plasminogen activator. Acta Radiol 56 : 1119-1126, 2015

32. Zhang G, Zhang JH, Qin X : Effect of weekend admission on in-hospital mortality after subarachnoid hemorrhage in Chongqing China. Acta Neurochir Suppl 110(Pt 1) : 229-232, 2011 